\title{
BMJ Open Quality Improving routine outpatient monitoring for patients with sickle-cell disease on hydroxyurea
}

\author{
Joel Ward, Natasha Lewis, Dimitris A Tsitsikas
}

To cite: Ward J, Lewis N, Tsitsikas DA. Improving routine outpatient monitoring for patients with sickle-cell disease on hydroxyurea.BMJ Open Quality 2018;7:e000218. doi:10.1136/ bmjoq-2017-000218

Received 28 September 2017 Revised 19 December 2017 Accepted 30 December 2017

Check for updates

Haemoglobinopathy Service, Homerton University Hospital NHS Foundation Trust, London, UK

Correspondence to

Dr Joel Ward; joel.ward@nhs.net

\section{ABSTRACT}

Hydroxyurea is the gold standard treatment for prevention of vaso-occlusive crises in patients with sickle-cell anaemia. It has a narrow therapeutic index and dangerous side effects including cytopenias. There is high variation in dose-response across the population. Therefore, a robust outpatient monitoring programme is crucial to ensure efficacy and safety of treatment. However, there has historically been difficulty engaging the target population in regular laboratory test monitoring programmes. This project aimed to ensure that all patients on hydroxyurea had routine blood tests at least once every 2 months which were reviewed and acted upon within the 3-year project life cycle. A specialist haematology nurse prescriber clinic service was introduced, first informally, and then formally to take blood tests, alter medication dosing, prescribe it and then write a clinic letter. The mean number of tests per patient per year rose from 0.21 at baseline to 9.05 after 2 years of the formal nurse prescriber clinic. This led to an associated increase in dose changes from 0.23 to 1.45 per patient per year. This improved the number of patients on the optimum dose of hydroxyurea. Furthermore, due to increased confidence in the outpatient monitoring, the total number of people being prescribed hydroxyurea increased from 26 to 42. Restriction of prescriptions to only those enrolled in the service has prevented unmonitored patients being at risk of the potential toxicities associated with doses that are too high. The introduction of a formal nurseled clinic has improved the safety, efficacy and compliance and increased the number of patients on the gold standard preventative treatment for vaso-occlusive crises in sicklecell anaemia.

\section{PROBLEM}

Hydroxyurea is used as a disease-modifying agent in patients with sickle-cell anaemia (SCA) and is the gold standard treatment for the prevention of vaso-occlusive crises (VOC). ${ }^{12}$ Given its efficacy in SCA, it is also recommended for patients with other forms of sickle-cell disease (SCD) who suffer recurrent VOCs. Close routine monitoring to ensure both safety and efficacy of treatment is required. However, it is widely recognised that there is substantial difficulty engaging the patient population with the routine laboratory monitoring and dose adjustments $^{3}$ required to ensure safety and optimise efficacy as long-term compliance is required before any clinical benefit is yielded.

Homerton University Hospital is a specialist haemoglobinopathy service within London and has a case load of 360 patients with SCD with one of the highest rates of emergency hospitalisation for VOC. ${ }^{4}$ In 2013, when this project began, there was no routine outpatient monitoring service for those patients on hydroxyurea. Therefore, at routine outpatient haematology appointments it was difficult to assess medication compliance, ensure correct dosing and react in a timely fashion to dangerous cytopenias.

This project aimed to ensure that all patients on hydroxyurea had routine blood tests at least once every 2 months which were reviewed and acted on within the 3-year project life cycle.

\section{BACKGROUND}

SCD is the fastest growing and most common inherited genetic disorder in England, estimated to affect 1 in 2000 births and a total of 12500 patients. $^{5} \mathrm{SCD}$ is caused by the inheritance of the sickle-beta globin gene, in homozygous form (HbSS), in conjunction with haemoglobin $\mathrm{C}$ (HbSC), $\beta$-thalassemia (HbS $\beta$-thal) or other inherited pathological haemoglobin genotypes. ${ }^{6} \mathrm{SCD}$ is characterised by intermittent vaso-occlusive events and chronic haemolytic anaemia. The sickle-shaped red blood cells (RBC) become distorted and rigid, causing occlusion of small arterioles and capillaries leading to downstream ischaemia and infarction. The deformed RBCs are also fragile, undergoing spontaneous haemolysis from the trauma of circulation. ${ }^{6}$

The major hallmarks of SCD are episodic painful crises which account for the majority of hospital admissions in the population. ${ }^{7}$ An adult patient's pain rate correlates with early death, with episodes increasing in frequency with age. ${ }^{8}$ 
Hydroxyurea has been shown to significantly reduce the rate of VOCs as well as the incidence of the acute chest syndrome in patients with SCA. ${ }^{9}$ One of its main ways of action is by stimulating fetal haemoglobin $(\mathrm{HbF})$ synthesis. This leads to reduction of the intracellular $\mathrm{HbS}$ concentration which in turn reduces $\mathrm{HbS}$ polymerisation. ${ }^{10}$ Hydroxyurea, like warfarin, has unpredictable pharmacokinetics and a narrow therapeutic index so therefore requires dose titration to the individual patient it is being used in, with careful monitoring of response. Overdosing can lead to myelosuppression, most commonly neutropenia, but associated thrombocytopenias and anaemias also occur. ${ }^{11}$ These are reversible on cessation of therapy and lower dose treatment is still likely to be effective in preventing sickling. Hydroxyurea is also significantly teratogenic and requires contraceptive use until 3 months after treatment. At the same time, efficacy increases when the highest tolerated dose, defined by the development of significant cytopenias, is used. ${ }^{12}$

It is widely recognised within the field that hydroxyurea has many provider and patient-related barriers preventing achievement of the benefits demonstrated in clinical trials. ${ }^{3}$ The patient group is difficult to engage in regular monitoring and strict compliance-both of which are required for optimum efficacy as well as safety. Therefore, this leads to practitioners being reticent to place those who may stand to benefit from hydroxyurea on the therapy.

Existing work in this field has focused on improving adherence to hydroxyurea such as through reminder text messages as opposed to improving monitoring. ${ }^{13}$ There are no evidence-based consensus monitoring recommendations but expert opinion suggests that patients need to be more intensely monitored in the first 6 months while the drug reaches peak effect. ${ }^{13}$ Thereafter, greater intervals between blood tests can be permitted. ${ }^{13}$ There are no other publications in the PubMed database detailing a nurse-led clinic specifically for the routine monitoring and dose adjustment of hydroxyurea. However, nurse-led clinics have been successfully used in other areas of Medicine, including routine monitoring of warfarin which has a similarly narrow therapeutic index.

\section{MEASUREMENT}

The number of outpatient blood tests was the primary measurement as this reflected whether patients were receiving regular outpatient monitoring of their blood results. However, secondary measurements were obtained such as HbF, mean corpuscular volume (MCV), the number of dose changes and the neutrophil count. MCV, which increases with the use of hydroxyurea, and $\mathrm{HbF}$ are markers of compliance with treatment. An increased number of dose changes indicates that test results were being used to appropriately titrate dose to response. The neutrophil count can be used to ascertain whether effective dosing has been reached-a count $\geq 5 \times 10^{9} / \mathrm{L}$ suggests that the dose can be increased, while a value

\begin{tabular}{|c|c|c|c|c|}
\hline Patient & Age & Gender & Genotype & Indication \\
\hline 1 & 50 & $\mathrm{~F}$ & $\mathrm{HbSS}$ & RPC \\
\hline 2 & 27 & $M$ & HbSS & RPC \\
\hline 3 & 40 & $M$ & $\mathrm{HbSS}$ & RPC \\
\hline 4 & 53 & $\mathrm{~F}$ & $\mathrm{HbS} \beta O$ & RPC \\
\hline 5 & 48 & $\mathrm{~F}$ & HbSS & RPC \\
\hline 6 & 33 & M & $\mathrm{HbS} \beta 0$ & $\mathrm{SSP}^{*}$ \\
\hline 7 & 27 & $M$ & $\mathrm{HbSS}$ & RPC \\
\hline 8 & 48 & $M$ & $\mathrm{HbE} \beta O$ & $\begin{array}{l}\text { Improving } \\
\text { anaemia }\end{array}$ \\
\hline 9 & 30 & $M$ & $\mathrm{HbSS}$ & RPC \\
\hline 10 & 56 & M & $\mathrm{HbSC}$ & RPC \\
\hline 11 & 31 & M & $\mathrm{HbSS}$ & RACS \\
\hline 12 & 44 & $\mathrm{~F}$ & $\mathrm{HbSS}$ & $\mathrm{RPC}$ \\
\hline 13 & 33 & $\mathrm{~F}$ & $\mathrm{HbSC}$ & $\mathrm{RPC}$ \\
\hline 14 & 32 & $\mathrm{~F}$ & $\mathrm{HbSS}$ & RPC \\
\hline 15 & 30 & M & $\mathrm{HbSS}$ & SSP* $^{*}$ \\
\hline 16 & 32 & M & $\mathrm{HbSS}$ & RPC \\
\hline 17 & 24 & M & $\mathrm{HbSS}$ & RPC \\
\hline 18 & 51 & $\mathrm{~F}$ & $\mathrm{HbSS}$ & SCN \\
\hline 19 & 67 & $\mathrm{~F}$ & $\mathrm{HbSC}$ & RPC \\
\hline 20 & 20 & $\mathrm{~F}$ & $\mathrm{HbSS}$ & RPC \\
\hline 21 & 47 & $\mathrm{~F}$ & HbSS & $\mathrm{RPC}$ \\
\hline 22 & 47 & $\mathrm{~F}$ & $\mathrm{HbSS}$ & RPC \\
\hline 23 & 34 & $\mathrm{~F}$ & $\mathrm{HbSS}$ & RPC \\
\hline 24 & 33 & $\mathrm{~F}$ & $\mathrm{HbSS}$ & RPC \\
\hline 25 & 42 & $\mathrm{~F}$ & $\mathrm{HbSS}$ & RPC \\
\hline 26 & 27 & $\mathrm{~F}$ & $\mathrm{HbSS}$ & RPC \\
\hline 27 & 25 & $M$ & $\mathrm{HbSS}$ & RPC \\
\hline 28 & 48 & $\mathrm{~F}$ & $\mathrm{HbSS}$ & RPC \\
\hline 29 & 44 & $\mathrm{~F}$ & $\mathrm{HbSS}$ & RPC \\
\hline 30 & 44 & $\mathrm{~F}$ & $\mathrm{HbSS}$ & $\mathrm{RPC}$ \\
\hline 31 & 23 & $\mathrm{~F}$ & HbSS & RPC \\
\hline
\end{tabular}

*Secondary stroke prevention, transfusions declined/ contraindicated.

RACS, recurrent acute chest syndrome; RPC, recurrent painful crises; SCN, sickle cell nephropathy; SSP, secondary stroke prevention.

of $<2 \times 10^{9} /$ Lmay require dose reduction; neutrophils $<0.5 \times 10^{9} / \mathrm{L}$ pose significant risk for neutropenic sepsis and the drug has to be temporarily discontinued. The optimal range is between 2 and $5 \times 10^{9} / \mathrm{L}$.

Only patients with complete data for at least 1 year were included in this analysis. We have currently 42 patients on hydroxyurea; of these, 11 are not evaluable as we have data for less than 1 year. The demographics for evaluable patients are summarised in table 1 .

Blood test results since 2009 are available on the electronic patient record computer system. Data were 
collected retrospectively at year intervals to analyse whether the implemented interventions were effective. Inpatient blood test results were excluded as although they could be used to confirm therapeutic levels were being used, they are not part of a structured and reliable outpatient monitoring programme to ensure safety and efficacy of treatment.

Prior to this project, there was no formal monitoring of hydroxyurea patients. Prescriptions were started at outpatient haematology clinics which general practitioners (GP) were expected to continue. However, they would not be able to change the doses and their monitoring was not fed back to the haematology outpatient clinics where decisions were being made about treatment. Furthermore, patients often presented to the Haematology Day Unit (HDU) and had repeat prescriptions by junior doctors without appropriate review.

This unstructured approach is reflected in the baseline measurements prior to the start of this project. There are only five outpatient results from all of the 24 patients who were on hydroxyurea across the whole year prior to the start of intervention. These are unsuitable for closer analysis of the compliance or efficacy due to the small data sample size.

\section{DESIGN}

The project team consisted of the authors which comprise a junior doctor working at the Homerton Hospital, a specialist haematology nurse prescriber and a haematology consultant with a special interest in haemoglobinopathies. Wider input was sought from the rest of the haematology department and patient input when required.

The main focus was on creating a reliable monitoring solution to observe compliance and prevent dangerous adverse complications of treatment.

Our aim was to create a designated outpatient setting where blood tests are taken, results reviewed and prescriptions issued. GPs would no longer be expected to prescribe hydroxyurea in order to optimise engagement with the outpatient monitoring and also to minimise risk: if patients are not appropriately monitored, then they have no medication to take, hence not at risk of adverse effects from overmedication.

\section{STRATEGY}

In our first plan-do-study-act (PDSA) cycle, we aimed to use the HDU where the majority of sickle cell patients frequently attended to receive analgesia prescriptions as a one-stop service for having bloods taken, results reviewed and then issuing of the hydroxyurea prescriptions. This was coordinated by a nurse specialist (not a nurse prescriber). Patients recommended for hydroxyurea therapy by a consultant haematologist were booked to attend the day unit by the haematology team, but this was not a formal clinic appointment. Patients who did not have recent blood results (in the last 2 months) or who had not attended routine haematology clinics were also booked onto the day unit. However, patients did not receive letters of appointments or reminder texts by the trust as is the policy for all outpatient appointments; the time and date were only informally communicated to them at the time of booking. As a result, attendance was poor so the nurse had to send text messages to patients reminding them to attend.

These informal appointments were often made at short notice, dependent on nurse availability and during the day, which precluded any of the patient population who were at work (an important goal of treatment) or who had regular time commitments on these days from attending. There were no protected slots allocated in the HDU schedule for these specialist haematology sessions, resulting in space only being available in otherwise quiet periods. Unfortunately, this led to the service being inflexible with regard to appointments. Although there was some engagement, most blood tests were frequently taken opportunistically from patients presenting for analgesia in early crises, which was an improvement from those requiring admission but did not constitute a routine outpatient monitoring service. Results reflected an improvement in blood test monitoring but there was limited documentation and attendance was poorer than expected. Furthermore, as the nurse could not prescribe, she could not function independently and prescriptions were still required to be issued by junior doctors on the day unit or by GPs.

In our second PDSA cycle, a formal nurse prescriber-led hydroxyurea outpatient clinic was created. This still took place in HDU but with allocated space and time as well as appropriate clerical support. In contrast to the first cycle, the nurse leading this clinic was an appropriately trained nurse prescriber. The nurse was able to function independently (leading to a more efficient service) because she was able to issue prescriptions without requiring junior doctor input. Patients were given scheduled outpatient appointments where blood tests were taken, processed urgently and then reviewed with the results as part of a wider consultation to review side effects. Patients had dose adjustments, prescriptions were issued by the nurse and then another appointment was arranged. Clinic letters were written and copied to the haematology consultant, improving documentation and keeping the GP and specialist in charge of a patient's care updated. The scheduled nature allowed patients to make provisions in advance to attend.

\section{RESULTS}

There was a significant increase $(\mathrm{P}<0.05$ using analysis of variance statistical analysis) in the mean number of outpatient tests per year from the baseline (0.21 mean test) and informal clinic (1.58 mean test) to the formal clinic (7.42 and 9.05 mean tests, respectively). This is displayed in figure 1 . 

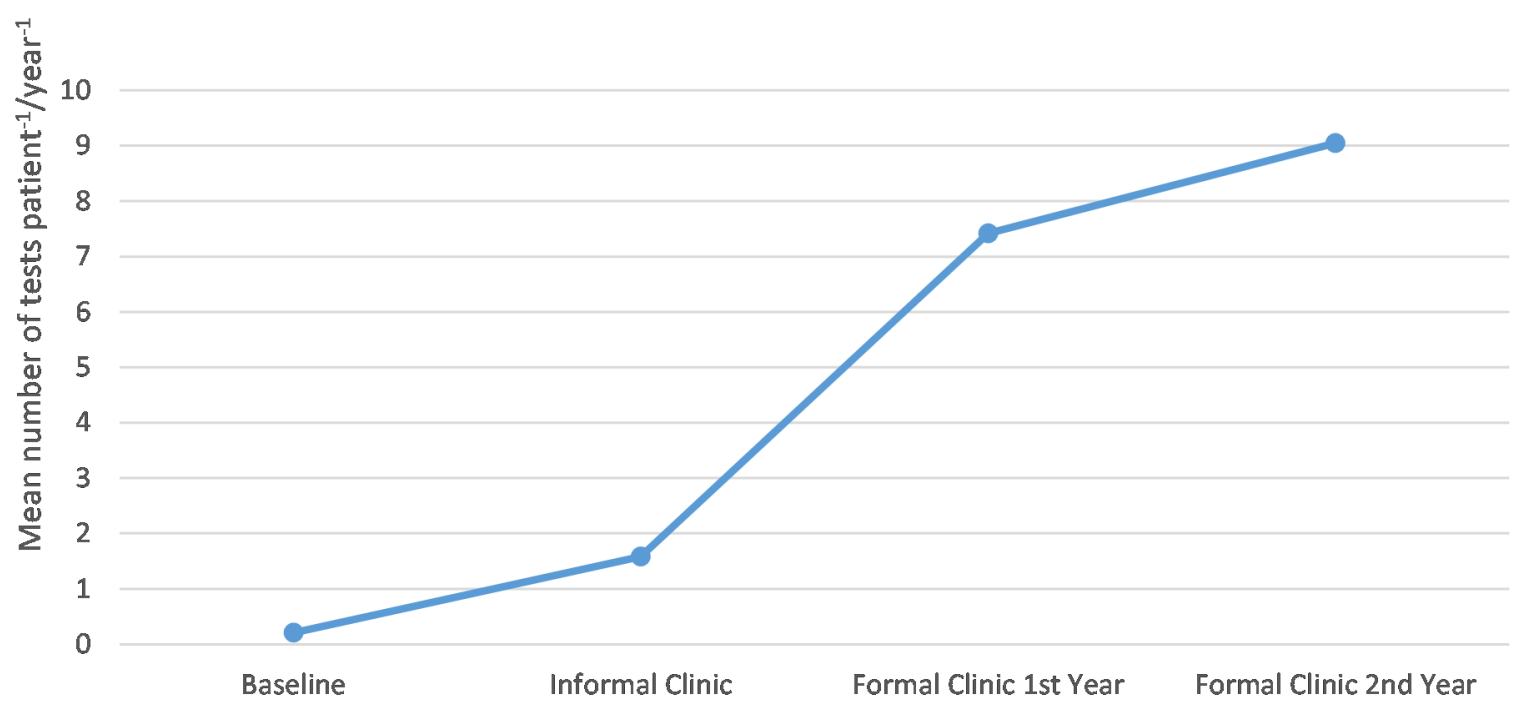

Intervention

Figure 1 A graph showing mean number of outpatient tests per patient per year.

There was also a notable increase in the number of mean dose changes per patient per year, rising from 0.23 during the informal clinic to 1.57 at peak in the first year of the formal clinic. This is displayed in figure 2.

There was improvement in the mean $\mathrm{HbF}$ (from 10.07 to 14.50) and MCV (from 86.01 to 94.47) across the monitored period, indicating that patients were more compliant with treatment, although the study was not powered or designed to show significance. These results, along with neutrophil counts and sample sizes, are shown in table 2.

As far as the neutrophil count is concerned, the number of $\%$ tests in the subtherapeutic range greater than 5 fell from the informal clinic to the formal clinic from 32.10 to 17.53 in the first year and 20.93 in the second year. During this period, there were no other changes involving hydroxyurea management to account for these results. Furthermore, the haematology consultants reported more confidence in starting patients on hydroxyurea, the number of these patients increasing from 26 to 42 .

\section{LESSONS AND LIMITATIONS}

The key lessons to take away from this project can be summarised as follows:

1. Routine outpatient monitoring for patients on hydroxyurea can be improved using a nurse prescriberled clinic.

2. Formal clinics, although resource intensive, produce a more reliable and structured environment for routine monitoring. Once the clinic is established, the intervention is sustainable as it becomes part of the standard service operation. The only potential limiting step is the availability of nurse prescribers. Nurse prescribers can be of great value in specialist haemoglobinopathy services and encouraging nurses to become pre-

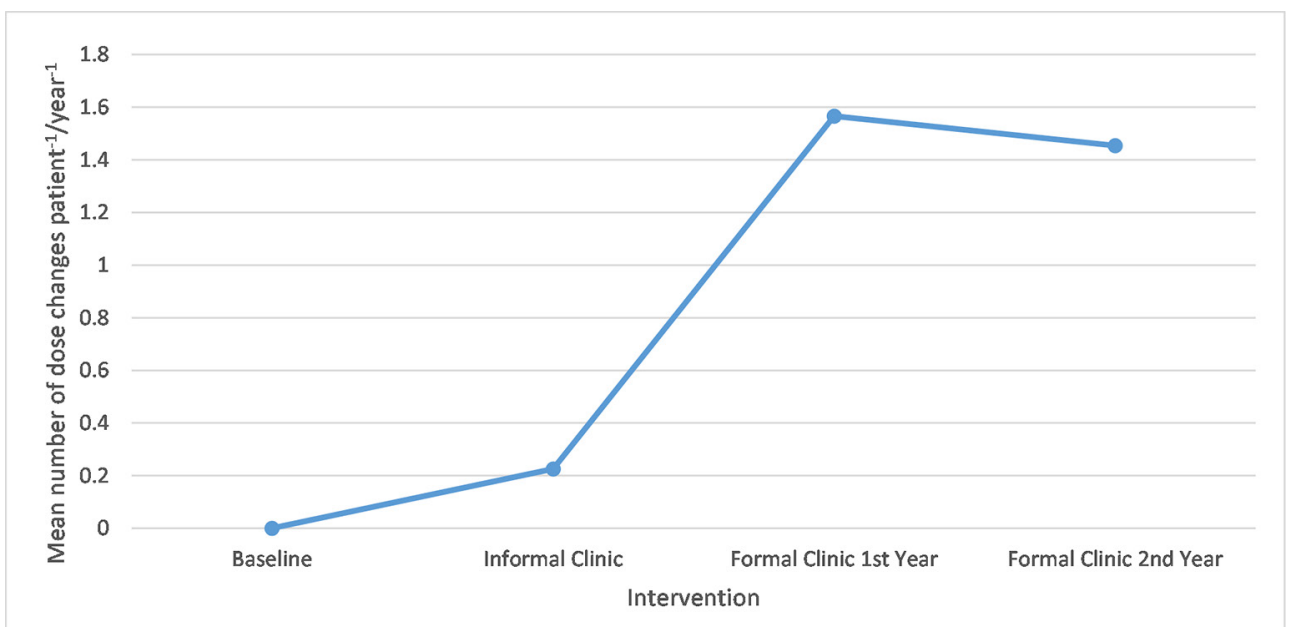

Figure 2 A graph showing mean number of dose changes per patient per year. 
Table $2 \mathrm{MCV}$, mean $\mathrm{HbF}$ and neutrophil counts

\begin{tabular}{|c|c|c|c|c|c|c|}
\hline & \multirow[b]{2}{*}{ Mean HbF } & \multirow[b]{2}{*}{ MCV } & \multicolumn{4}{|c|}{ Neutrophils } \\
\hline & & & $>5 \%$ tests & $2 \%-5 \%$ tests & $<2 \%$ tests & $<0.5 \%$ tests \\
\hline Baseline & - & - & - & - & - & - \\
\hline Formal clinic first year & 12.89 & 93.23 & 17.53 & 65.83 & 16.64 & 0.00 \\
\hline $\begin{array}{l}\text { Formal clinic second } \\
\text { year }\end{array}$ & 14.50 & 94.47 & 20.93 & 57.22 & 21.85 & 0.00 \\
\hline
\end{tabular}

MCV, mean corpuscular volume.

scribers should be strongly supported. In our service, two more clinical nurse specialists are currently taking the relevant course.

3. Regular monitoring increases treatment efficacy through compliance and optimisation of drug dosing.

4. Clinicians are more confident in prescribing hydroxyurea knowing that dangerous side effects can be avoided by the formal monitoring programme.

5. Potential toxicities are avoided by restricting hydroxyurea prescriptions only to those participating in the formal monitoring programme.

The implications of these lessons enabled more patients to receive the gold standard therapy for preventing VOC, reducing mortality, morbidity and associated healthcare costs from admissions (discussed in further detail below). This intervention is widely generalisable as most haematology units run outpatient services and blood tests, with these being the only barriers to entry.

This is a single-centre retrospective analysis of a structural service intervention to improve safety and efficacy of standard clinical practice and as such has several limitations.

All patients receiving hydroxyurea, irrespective of indication, were eligible for analysis provided they had at least 1 year of complete data. Engagement and compliance were measured mainly by two surrogate markers: number of outpatient blood tests and number of dose changes. Even though our data strongly suggest significant overall improvement in patient engagement and compliance, the retrospective nature of the analysis and use of indirect markers cannot detect interpatient variability as we do not have data on individual patient refill history. This means that even though efficacy appears improved for the group we cannot comment on whether every patient benefited equally. However, the discontinuation of prescriptions outside the confines of the dedicated clinic ensured safety for all patients even if not compliant.

Even though improved from baseline, a substantial number of the neutrophil results after 2 years of the formal clinic remain higher than desired. We cannot draw any firm conclusions from that as it may reflect ongoing suboptimal compliance by some patients but lack of dose escalation may have also been based on other clinical factors. During the project, the days of clinic sessions were modified depending on specialist nurse and patient availability to improve the options available for patients. If the project were to be repeated again the main change would have been to introduce a formal clinic from the start.

\section{CONCLUSION}

This project aimed that all patients on hydroxyurea had routine blood tests at least once every 2 months which were reviewed and acted on within the 3-year project life cycle. The increase in the mean number of blood tests per year over the project life cycle achieved this ambition. Markers of compliance indicated that more patients were complying with treatment and there were no detected episodes of severe neutropenia. Regular monitoring allows optimisation of doses, as reflected by the increased number of dose changes from 0.23 to 1.57 from the informal to the formal nurse clinic. This decreased the year after to 1.45 , perhaps reflecting that the majority of patients were already established on optimum doses of therapy.

Although there is the cost of setting up and funding the clinic, hydroxyurea is known to reduce VOC by $50 \%$. Successful maintenance of hydroxyurea in therapeutic range could be expected to translate into an associated reduction in hospital utilisation, which offsets the cost of the clinic.

Now that the clinic has been set up and funded, the change is sustainable as it will continue to run while hydroxyurea is a relevant and useful treatment in the prevention of VOC in patients with SCD. This clinic should be replicated at other haemoglobinopathy units.

This project elegantly demonstrates that it is possible to overcome logistical issues which can prevent benefits seen in randomised hydroxyurea trials from being mirrored in the patient population with the introduction of a cost-effective nurse-led outpatient monitoring clinic.

Contributors JW designed the project, collected the data and wrote the paper. $\mathrm{NL}$ collected the data. DAT codesigned the project and critically reviewed the manuscript.

Funding This research received no specific grant from any funding agency in the public, commercial or not-for-profit sectors.

Competing interests None declared.

Provenance and peer review Not commissioned; internally peer reviewed. 
Open Access This is an Open Access article distributed in accordance with the Creative Commons Attribution Non Commercial (CC BY-NC 4.0) license, which permits others to distribute, remix, adapt, build upon this work non-commercially, and license their derivative works on different terms, provided the original work is properly cited and the use is non-commercial. See: http://creativecommons.org/ licenses/by-nc/4.0/

(c) Published by the BMJ Publishing Group Limited. For permission to use (where not already granted under a licence) please go to http://www.bmj.com/company/ products-services/rights-and-licensing/

\section{REFERENCES}

1 Nevitt SJ, Jones AP, Howard J. Cochrane Cystic Fibrosis and Genetic Disorders Group. Hydroxyurea (hydroxycarbamide) for sickle cell disease. Cochrane Database Syst Rev 2017;106:CD002202.

2. Claster S, Vichinsky EP. Managing sickle cell disease. BMJ 2003;327:1151-5.

3. Brandow AM, Panepinto JA. Hydroxyurea use in sickle cell disease: the battle with low prescription rates, poor patient compliance and fears of toxicities. Expert Rev Hematol 2010;3:255-60.

4. Aljuburi G, Laverty AA, Green SA, et al. Trends in hospital admissions for sickle cell disease in England, 2001/02-2009/10. J Public Health (Oxf). Dec 2012;34:570-6.

5. Streetly A, Latinovic R, Henthorn J. Positive screening and carrier results for the England-wide universal newborn sickle cell screening programme by ethnicity and area for 2005-07. J Clin Pathol 2010;63:626-9.

6. Hoffmann RG. Hematology: basic principles and practice. ed 4. Philadelphia: Elsevier Churchill Livingstone, 2005.

7. Platt OS, Thorington BD, Brambilla DJ, et al. Pain in sickle cell disease. Rates and risk factors. N Engl J Med 1991;325:11-16.

8. Platt OS, Brambilla DJ, Rosse WF, et al. Mortality in sickle cell disease. Life expectancy and risk factors for early death. $N$ Engl J Med 1994;330:1639-44.

9. Charache S, Terrin ML, Moore RD, et al. Effect of Hydroxyurea on the Frequency of Painful Crises in Sickle Cell Anemia. N Engl J Med Overseas Ed 1995;332:1317-22.

10. Charache S. Mechanism of action of hydroxyurea in the management of sickle cell anemia in adults. Semin Hematol 1997;34:15-21.

11. Strouse JJ, Lanzkron S, Beach MC, et al. Hydroxyurea for sickle cell disease: a systematic review for efficacy and toxicity in children. Pediatrics 2008;122:1332-42.

12. Zimmerman SA, Schultz WH, Davis JS, et al. Sustained long-term hematologic efficacy of hydroxyurea at maximum tolerated dose in children with sickle cell disease. Blood 2004;103:2039-45.

13. Estepp JH, Winter B, Johnson M, et al. Improved hydroxyurea effect with the use of text messaging in children with sickle cell anemia. Pediatr Blood Cancer 2014;61:2031-6.

14. Strouse JJ, Heeney MM. Hydroxyurea for the treatment of sickle cell disease: efficacy, barriers, toxicity, and management in children. Pediatr Blood Cancer 2012;59:365-71. 